\title{
Precursory atmospheric circulations with Rossby wave trains leading to Eurasian extreme cold events
}

\section{Wenqin zhuo}

Ocean University of China

Fei Huang ( $\boldsymbol{\nabla}$ huangf@mail.ouc.edu.cn )

Ocean University of China https://orcid.org/0000-0002-1119-9081

\section{Ruichang Ding}

Ocean University of China

Jin Luo

Ocean University of China

\section{Research Article}

Keywords: Eurasia, extreme cold events, Rossby wave packets, downstream development

Posted Date: September 3rd, 2021

DOl: https://doi.org/10.21203/rs.3.rs-849842/v1

License: (c) (i) This work is licensed under a Creative Commons Attribution 4.0 International License. Read Full License 

to Eurasian extreme cold events

*Corresponding author: Fei Huang (huangf@ouc.edu.cn)

${ }^{1}$ Key Laboratory of Physical Oceanography, Institute for Advanced Ocean Study, Ocean University of China, Qingdao, China.

${ }^{2}$ College of Oceanic and Atmospheric Sciences, Ocean University of China, Qingdao, China

${ }^{3}$ Qingdao National Laboratory for Marine Science and Technology, Qingdao, China. 
Abstract

This work examines precursory atmospheric circulations with various wave trains contributing to extreme cooling over central Eurasia in boreal winter from 1979-2016 based on the ERA-Interim dataset. The empirical orthogonal function (EOF) method is used to classify the anomalous sea level pressure field averaged in two weeks prior to extreme cooling. Based on the classification, three types of precursory atmospheric circulation patterns are named according to the origins of wave trains, and their formation mechanisms are revealed as well. Type1: Baffin Bay-origin pattern, which forms in the downstream development of Rossby wave packets generated from the downward stratospheric energy transmission over the Baffin Bay. Type2: Pacific-origin pattern, similar to a Eurasian (EU) teleconnection pattern, arises at the exit area of the westerly jet in the central North Pacific where cyclonic shear exists; then it develops along the northerly westerly jet over the North Atlantic, which may act as a waveguide to the Eurasian continent. Type 3: Atlantic-origin, manifests as the negative phase of type 2, consistent with the Scandinavian (SCAND) pattern, which may results from the air-sea interaction induced by the warm anomaly of sea surface temperature in the middle of North Atlantic. In conclusion, the three types of precursory atmospheric wave train patterns that bring extreme cooling to Eurasia possess diverse disturbing sources and development mechanisms. The results, which are investigated based on a quasibiweekly time scale, deepen our understanding of the atmospheric genesis of extreme weather and have specific indicative significance to improve the technique of extended forecast. 
The research is supported by National Key Scientific Research Program of China (2019YFA0607004),

62 the National Science Foundation of China (42075024) and Shandong Natural Science Foundation Project

63 (ZR2019ZD12)

\section{Conflicts of interest/Competing interests}

65 All the authors declare no conflicts of interest and competing interests

66 Availability of data and material

67 All the data and material are available

68 Code availability

69 The code is not available

\section{Ethics approval}

$71 \quad$ Not applicable

\section{Consent to participate}

73 All the authors consent to participate this work

74

\section{Consent for publication}

All the authors consent the work for publication

(1)

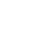

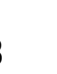

79

80

81

82

83

84

85

86




\section{Introduction}

Frequently extreme cooling occurred in the boreal winter over central Eurasia in recent years (Cohen et al. 2012,2014; Zhang et al. 2012; Lu et al. 2016; Ma et al. 2018; Mori et al. 2019; Zheng et al.,2021). The mechanisms of extreme cold climate anomalies have been widely discussed. There are many studies that focus on the external compulsion factors, such as the Arctic amplification (Cohen et al. 2019), and sea ice melt owing to Arctic warming (Zhuo and Jiang,2020), the stratospheric influence (Kretschmer et al. 2018), the force of sea surface temperature over Atlantic (Luo et al. 2019), etc. However, the ultimate impact factors of extreme weather still have to be traced back to the general atmospheric circulation, that is, the propagation of Rossby waves, which transfer energy, moisture, and momentum across long distances (Wallace and Gutzler 1981).

There are many atmospheric teleconnections that can induce significant climate anomalies over the Eurasian continent. For example, the Eurasian (EU) pattern (Wallace and Gutzler,1981), which shows like west-east-oriented wave train over Eurasia and can be further divided into the forms of Scandinavian (SCAND) pattern and East Atlantic/West Russia pattern (Barnston and Livezey, 1987). Those various patterns have distinct sources and formation mechanisms (Casado et al. 2009; Liu et al. 2014). Take the SCAND pattern, which is typically generated from the North Atlantic and can be classified into convection-preceded and convection-free types (Wang and Tan,2020). Besides, the North Atlantic Oscillation (NAO) pattern can also exert influence on the climate over Eurasia by affect the Arctic sea ice melt (Luo et al. 2016a, b). In addition to these typical teleconnection circulation patterns, the atmospheric wave trains can also propagate along the strong westerly jets (Hoskins and Ambrizzi 1993), which can serve as efficient Rossby waveguides (Chang and Yu 1999; Branstator, 2002). When a wave train extracts energy from mean flow, it is conducive to the further progress of the Rossby wave (Kosaka et al. 2009; Hu et al. 2018), and extreme weather occurred under the configuration of mature atmospheric circulation.

Under certain circumstances, Rossby waves can propagate from upstream to downstream along with the westerlies as Rossby wave packets (RWPs), which can be observed in the upper troposphere. To some extent, therefore, the evolution of Rossby wave can be a precursor to extreme weather (Wirth and Eichhorn,2014; Bosart et al. 2017; Wirth et al. 2018; Fragkoulidis et al. 2018; Grazzini et al. 2020). For example, Wirth and Eichhorn (2014) examined the statistical connection between surface cyclones over 

RWPs significantly increases the probability of downstream cyclone development. Grazzini et al. (2020) pointed out that the amplification of RWPs over the western North Atlantic can result in a downstream trough, which is highly related to the extreme precipitation events over Italy. The RWPs along the westerly jet in the upper troposphere may also impact the precipitation in the Yangtze River over China (Shi et al. 2009; Sun and Guan,2020). Areas of large RWP amplitude are found to be associated with an increased probability of extremes temperature in lower-tropospheric (Fragkoulidis et al. 2018). However, not every extreme weather event is necessarily related to an RWP precursor (Barton et al. 2016; Wirth et al. 2018). The climate affects variously when the dispersion degree and range of energy differ. Under certain conditions, other atmospheric signals, such as the downward propagation of AO (Gong et al. 2014), the anomalies of pressure extend from lower troposphere to stratosphere (Shi et al.,2021), were also conducive to Rossby wave train propagation and lead to extreme weather occurs.

Anyway, enhanced understanding of RWPs could contribute to improving the weather forecast, particularly with extreme weather conditions. Thus it is essential to examine the character of wave trains that can give rise to extreme cooling, which is of great significance in probing the systematic connection between precursory RWPs and severe climate and further improving the extended forecast technique. In this work, we will analyze the basic features and formation mechanisms of various wave trains that lead to extreme cooling over central Eurasia in winter, by selecting the extreme cold events and classifying the corresponding anomalous circulations in prior to cooling.

The dataset and methods are described in Section 2. Section 3 classifies the circulation of cold events into three types and presents corresponding circulation anomalies of each type. The characteristics and mechanisms of each category's events are discussed respectively in Section 4. Conclusions and discussions are presented in Section 5.

\section{Data and methods}

The daily mean ECMWF reanalysis (ERA)-Interim dataset (Dee et al. 2011) for boreal winter (December-February (DJF)) from 1979-2016 are used, with a horizontal resolution of $1^{\circ}$ latitude $\times 1^{\circ}$ longitude. Variables include the 2-m surface air temperature (SAT), sea level pressure (SLP), geopotential height, sea surface temperature (SST), surface turbulent heat flux (STHF (sensible plus latent)), zonal ( $u$ ) 
climatological mean for each calendar day at each grid point.

To investigate the mechanisms of Eurasia cooling, 29 extreme cold events are identified over central

149 Eurasia $\left(40^{\circ} \mathrm{N}-60^{\circ} \mathrm{N}, 60^{\circ} \mathrm{E}-120^{\circ} \mathrm{E}\right)$ where emerged a cooling trend in recent decades (Mori et al. 2019).

150 An extreme cold event is defined over a period when the domain-averaged SAT reaches the criterion of

151 the probability of occurrence less than $10 \%$ (namely, $253.49 \mathrm{~K}$ or $-19.66^{\circ} \mathrm{C}$ ) and persists for more than

1523 days. Besides, to avoid the non-independent circulation system, the interval between two cold events

153 needs to exceed 15 days (Wu et al. 2017). Lag 0 for a cold event is defined as the onset day when the

154 domain-averaged SAT index first reaches its criterion, and the life cycle of each event refers to the

155 number of consecutive days that meet the standard. The detail information and corresponding

156 classification results about each case, which will further describe in next section, are listed in the Table

1571.

158 Table 1. The information of onset date (yyyy-mm-dd) and life cycle (unit: days) and corresponding

159 category of each case

\begin{tabular}{cccccccc}
\hline Number & Onset date & Life cycle & Category & Number & Onset date & Life cycle & Category \\
\hline 1 & 19800126 & 14 & Type 1 & 16 & 20011209 & 4 & Type 3 \\
2 & 19810120 & 5 & Type 2 & 17 & 20021228 & 4 & Type 3 \\
3 & 19840121 & 17 & Type 2 & 18 & 20041223 & 6 & Type 2 \\
4 & 19841210 & 7 & Type 3 & 19 & 20050123 & 17 & Type 2 \\
5 & 19861224 & 3 & Excluded & 20 & 20060102 & 3 & Type 3 \\
6 & 19880121 & 6 & Type 3 & 21 & 20080110 & 20 & Type 3 \\
7 & 19880212 & 3 & Type 2 & 22 & 20100101 & 3 & Type 1 \\
8 & 19900115 & 5 & Type 3 & 23 & 20100202 & 12 & Type 3 \\
9 & 19911223 & 3 & Excluded & 24 & 20101221 & 3 & Type 1 \\
10 & 19940114 & 4 & Type 1 & 25 & 20110115 & 12 & Type 1 \\
11 & 19960110 & 7 & Type 3 & 26 & 20120117 & 17 & Type 2 \\
12 & 19980111 & 13 & Type 2 & 27 & 20121212 & 16 & Type 1 \\
13 & 20000102 & 7 & Excluded & 28 & 20140201 & 5 & Type 3 \\
14 & 20010103 & 10 & Type 1 & 29 & 20160117 & 6 & Type 1 \\
15 & 20010131 & 7 & Type 3 & & & & \\
\hline
\end{tabular}


related to cold events. For qualitative discussion, we perform Empirical Orthogonal Function (EOF) analysis to classify the atmospheric circulations. Furthermore, the wave activity flux (WAF) following Takaya and Nakamura et al. (2001), which is parallel to the local group velocity of stationary Rossby wave and can be used to describe the propagation of the atmospheric wave train, is calculated and expressed as follows:

$$
W=\frac{p \cos \varphi}{\partial U \mid} \cdot\left(\begin{array}{c}
\frac{U}{a^{2} \cos ^{2} \varphi}\left[\left(\frac{\partial \psi^{\prime}}{\partial \lambda}\right)^{2}-\psi^{\prime} \frac{\partial^{2} \psi^{\prime}}{\partial \lambda^{2}}\right]+\frac{V}{a^{2} \cos \varphi}\left[\frac{\partial \psi^{\prime} \partial \psi^{\prime}}{\partial \lambda}-\psi^{\prime} \frac{\partial^{2} \psi^{\prime}}{\partial \lambda \partial \varphi}\right] \\
\frac{U}{a^{2} \cos \varphi}\left[\frac{\partial \psi^{\prime} \partial \psi^{\prime}}{\partial \lambda}-\psi^{\prime} \frac{\partial^{2} \psi^{\prime}}{\partial \lambda \partial \varphi}\right]+\frac{V}{a^{2}}\left[\left(\frac{\partial \psi^{\prime}}{\partial \varphi}\right)^{2}-\psi^{\prime} \frac{\partial^{2} \psi^{\prime}}{\partial \varphi^{2}}\right] \\
\frac{f_{0}^{2}}{N^{2}}\left\{\frac{U}{a \cos \varphi}\left[\frac{\partial \psi^{\prime}}{\partial \lambda} \frac{\partial \psi^{\prime}}{\partial z}-\psi^{\prime} \frac{\partial^{2} \psi^{\prime}}{\partial \lambda \partial z}\right]+\frac{V}{a}\left[\frac{\partial \psi^{\prime}}{\partial \varphi} \frac{\partial \psi^{\prime}}{\partial z}-\psi^{\prime} \frac{\partial^{2} \psi^{\prime}}{\partial \varphi \partial z}\right]\right\}
\end{array}\right)
$$

where $\varphi, \lambda, \mathrm{z}$ denote latitude, longitude, vertical coordinate, respectively; a is Earth' radius, $f_{0}$ is Coriolis parameter, $p$ is pressure, $N^{2}$ is buoyancy frequency squared; $U, V$ denote the climatological zonal and meridional horizontal wind, and $\psi^{\prime}$ is anomaly of stream function.

Finally, two-tailed Student's t-test is used for statistically significant levels.

\section{Features of Eurasian extreme cold events and corresponding precursory atmospheric} wave train patterns

\subsection{Classification of Eurasian extreme cold events}

Considering the fact that there are various atmospheric circulations that cause Eurasia cooling (Horton et al. 2015; Hu et al. 2018; Wang and Tan 2020), we classify the circulation systems based on atmospheric in two weeks preceding the cold event. Figure 1a-b shows two leading modes of atmospheric circulation anomalies by using the EOF analysis on the composite SLP anomalies averaged in lag from -14 to -1 days. The first mode explains $26 \%$ of the variance, where the positive SLP anomalies dominate the Arctic circle and the center of action located in the southwest of Greenland, while the negative SLP anomalies dominate the area from western Atlantic to eastern Europe, resembling the northwestsoutheast negative phase of NAO. The second mode, which explains $15.2 \%$ of the variance, has a solid positive anomalous SLP center located at the Scandinavia peninsula, and the northeast Pacific to North Atlantic area are all controlled by the negative SLP anomalies.

According to these two leading modes of EOF analysis, 29 cold events are reclassified into three types. It should be noted that not only the PC time series (supplementary Fig. S1) but also the average SLP anomalies field of each case (Fig.S2) are referred to when categorizing the circulations, thus ensuring that the system affecting the cooling area has the greatest similarity to the EOF mode. Figure 
1c-f show the composite fields of anomalous SLP of each type after classification. The first type (type1,

Fig.1c) is similar to EOF1 mode, which exhibits the northwest-southeast negative phase of NAO, with 8 cases in total (Table 1). The second type (type 2, Fig.1d) like the negative phase of EOF2 mode and is similar to the EU pattern, which has one negative center of action around the Scandinavian Peninsula and two other centers of activity with opposite signs over the north Atlantic and Siberia area, consist of 7 cases (Table 1). The third type (type3, Fig.1e) is close to the positive phase of EOF2 mode, shows like the SCAND pattern, which has a positive center of action located at the Scandinavian Peninsula, consist of 11 cases (Table 1). In addition, there are three cases that exhibit the negative phase of EOF1 mode (Table 1), thus they are excluded in this paper due to the small sample size. In this way, all cases are classified into three types of cold events for qualitative discussion.

(a)

(b)
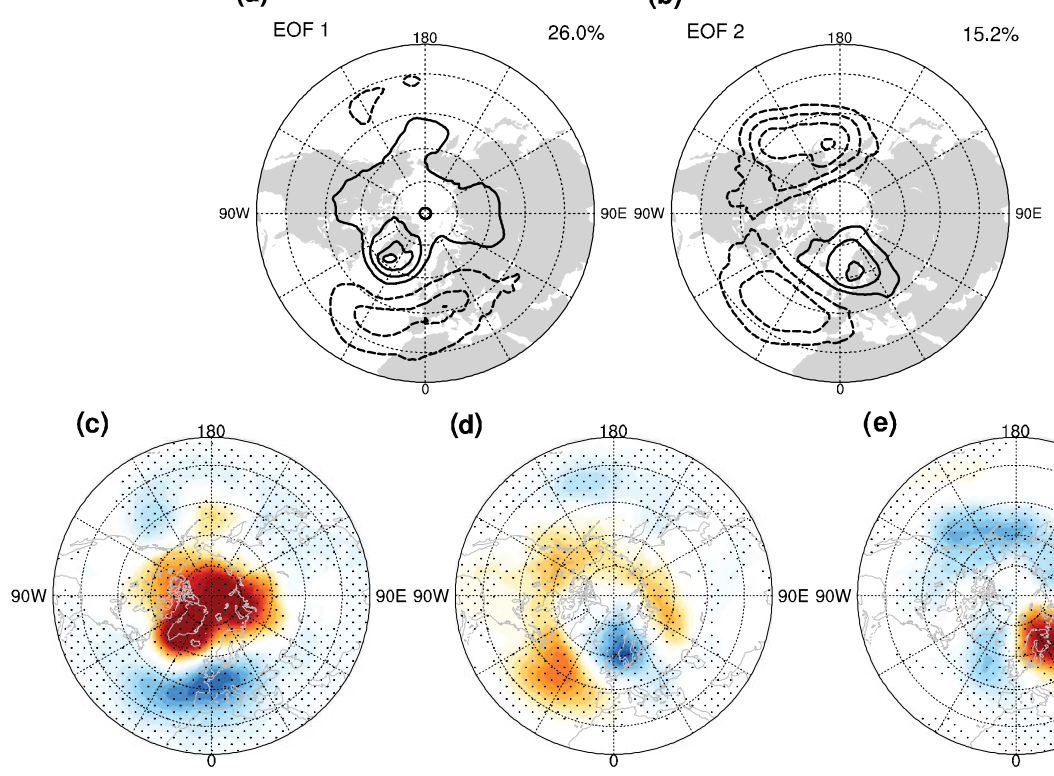

(d)

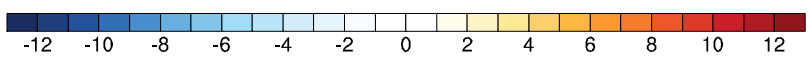

(d)

180

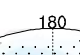

(e)

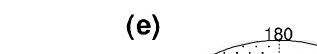

Fig. 1 a-b Spatial patterns of two leading EOF modes of anomalous SLP averaged in lag -14 to -1 days based on 29 cold events, explaining 26 and $15.2 \%$ of total variance, respectively; c-e Composite fields of anomalous SLP (unit: hPa) averaged in lag -14 to -1 days of $\mathbf{c}$ type1, $\mathbf{d}$ type2, e type3 event. The anomalies over stippled regions in c-e are statistically significant above $95 \%$ confidence level according to the Student's t test

The distribution of the cumulative negative temperature (multiplied by -1) during each case's life cycle and the related classification is shown in Fig.2 to detect the essential characteristics of three types of events. In general, it can be seen that the cold events occurred more frequently after the winter in 

attention (Zhang et al. 2012; Kug et al. 2015; Lu et al. 2016). Specifically, it shows that the type 1 event occurs more often in the winter after 2009/2010, while type 3 takes place more frequently between $1999 / 2000$ to 2008 , and the coldest case occurred in 2008. In the following, the three groups of 212 anomalous circulations after composition are discussed separately.

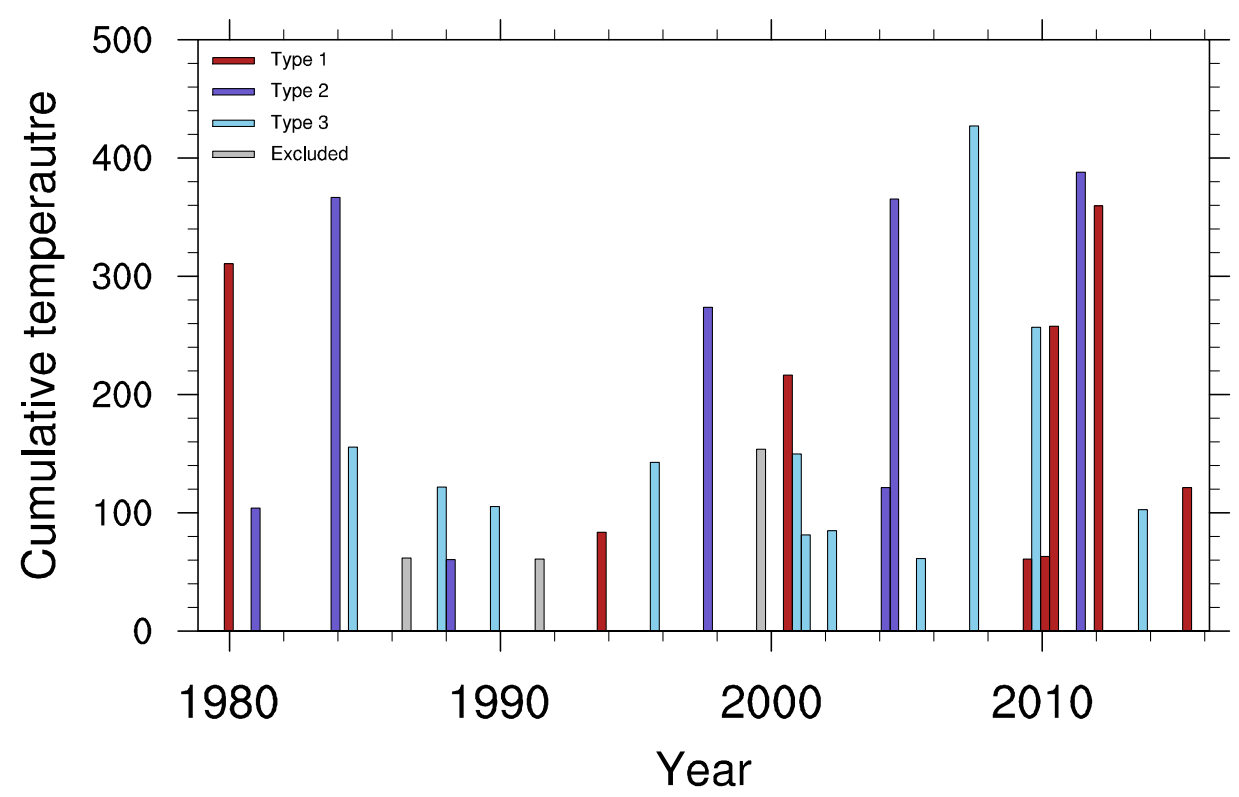

214 Fig. 2 Time series of cumulative negative temperature (multiplied by -1) of 29 cases and corresponding classification

\subsection{Corresponding atmospheric circulation anomalies}

Before analyzing the mechanisms of cold events, the evolution of anomalous 500-hPa geopotential height and SAT fields of three types of cold events over time is shown in Fig.3. It can be seen that the cooling situation can last for a week for all three events (lag 0-6 days in Fig.3a-c). Furthermore, for type 1 event (Fig.3a), a positive anomalous action center is located around over eastern Greenland at lag -12 days, as it continues to grow and strengthen, the downstream system over Eurasia also begins to evolve, and the cold anomalies appear over the north of central Eurasia at lag 0 days; After that, at lag 6 days, the upstream system over the Greenland decays, with the cold anomalies weaken and fade away. For type 2 event (Fig. 3b), clearly system appears at lag -6 days, with a wave train stretching from mid-North Pacific to the European continent; then, the upstream system degrades and a solid positive anomaly center located Ural Mountain area at lag 0 days, leading the outbreak of cooling over Eurasia. For type 3 event 
other opposite centers of action over the central Atlantic and Europe; as the anticyclone anomalies intensify, the wave train evolves into the mode like the SCAND teleconnection pattern (Barnston and

230 Livezey, 1987) at lag 0 days and brings cold anomalies into Eurasia. In general, though there is little 231 difference in the cooling situation of three types of events after lag 0 days, the atmospheric systems in 232 the prophase of cold events differ greatly. Therefore, in the next section, the generation mechanisms of three kinds of cold events will be examined respectively.
(a) Type1
(b) Type2
(c) Type3
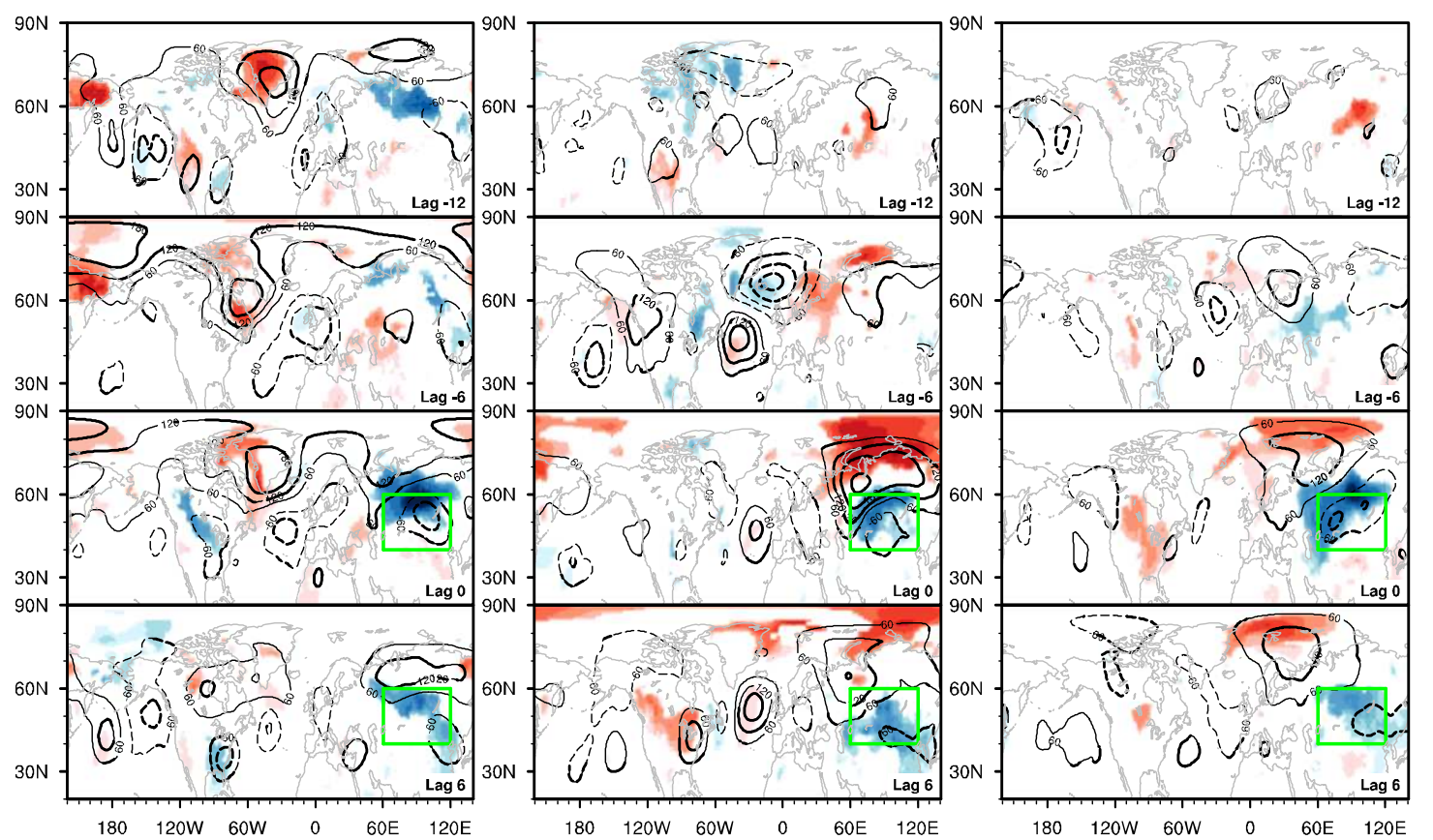

Fig.3 a-c Lead-lag composite of anomalous SAT (shading; unit: K) and 500-hPa geopotential height (contour; unit: gpm, $\mathrm{CI}=60 \mathrm{gpm}$ ) fields for the three type cold events from lag -12 to 6 days. The green box indicates the study area where the cold event occurs. The thick line and shaded area denote that the anomaly is statistically significant above the $95 \%$ level of confidence

\section{The formation mechanisms of the three types of wave trains}

In this section, the period of cold events is further divided into three stages, that is, stage 1: averaged

241 in lag -14 to -8 days, which represents the time that initial atmospheric signal begins; stage2: averaged

242 in lag -7 to -1 days, which on behalf of the development stage of atmospheric anomalies; stage 3 :

243 averaged in lag 0 to 6 days, indicating the occurrence of the cold event. In the following, we will discuss

244 the formation mechanisms of three types of cold events separately.

\section{1 type1: Baffin Bay-origin}


In general, the Rossby waves can be referred to by deviations from the zonal flow, which are usually

247 diagnosed by the meridional wind of upper-troposphere that can intuitively present the properties of 248 RWPs (Wirth et al. 2018). The group and phase velocity of RWPs can also be reflected on the Hovmoller 249 diagram of meridional wind, which can detect downstream development as a tool(Persson 2017). Fig.4 250 captures the structure of $v^{\prime}$ in horizontal, vertical and its Hovmoller diagram. In the mean $v^{\prime}$ fields of 251 three stages at 250-hPa (Fig.4a), two columns of distinct RWPs can be seen at the Aleutian Islands to the 252 northern Florida Peninsula $\left(170^{\circ} \mathrm{W}-60^{\circ} \mathrm{W}\right)$ and the Baffin Bay to northern Asia $\left(30^{\circ} \mathrm{W}-140^{\circ} \mathrm{E}\right)$. 253 Apparently, it is the one near the east $\left(30^{\circ} \mathrm{W}-140^{\circ} \mathrm{E}\right)$ that cause the cold anomaly of Eurasia. Therefore, 254 the Hovmoller diagram of the latitude band of this column RWPs (red box in Fig.4a) is shown in Fig.4b. 255 It can be seen that the first RWP generated at $60^{\circ} \mathrm{W}$ around lag -20 days and began to develop downstream. 256 At lag -10 days, a situation of larger group velocity than phase velocity can be identified, as shown by 257 the marked arrow (Fig.4b), which signifies a rapid downstream propagation of energy, resulting in the 258 cold event that occurred at lag 0 days. Then, the RWPs dissipate around lag 6 days, along with the 259 termination of the cold event. Furthermore, Fig 4c presents the vertical structure of four RWPs centers 260 labeled in Fig.4a at three stages. The strongest amplitude mainly shows in the upper troposphere, 261 consistent with the previous study (Krishnamurti et al. 1977). In addition, it is worth noting that the 262 RWPs reach the maximum amplitude at stage 2 rather than stage 3, i.e., before the outbreak of cold event, 263 which indicates that extreme weather may be just around the corner when the strong amplitude RWPs 264 signal emerges. In other words, it validates the role of downstream development of RWPs for cold events 265 (Chang and Yu 1999; Glatt et al. 2011).

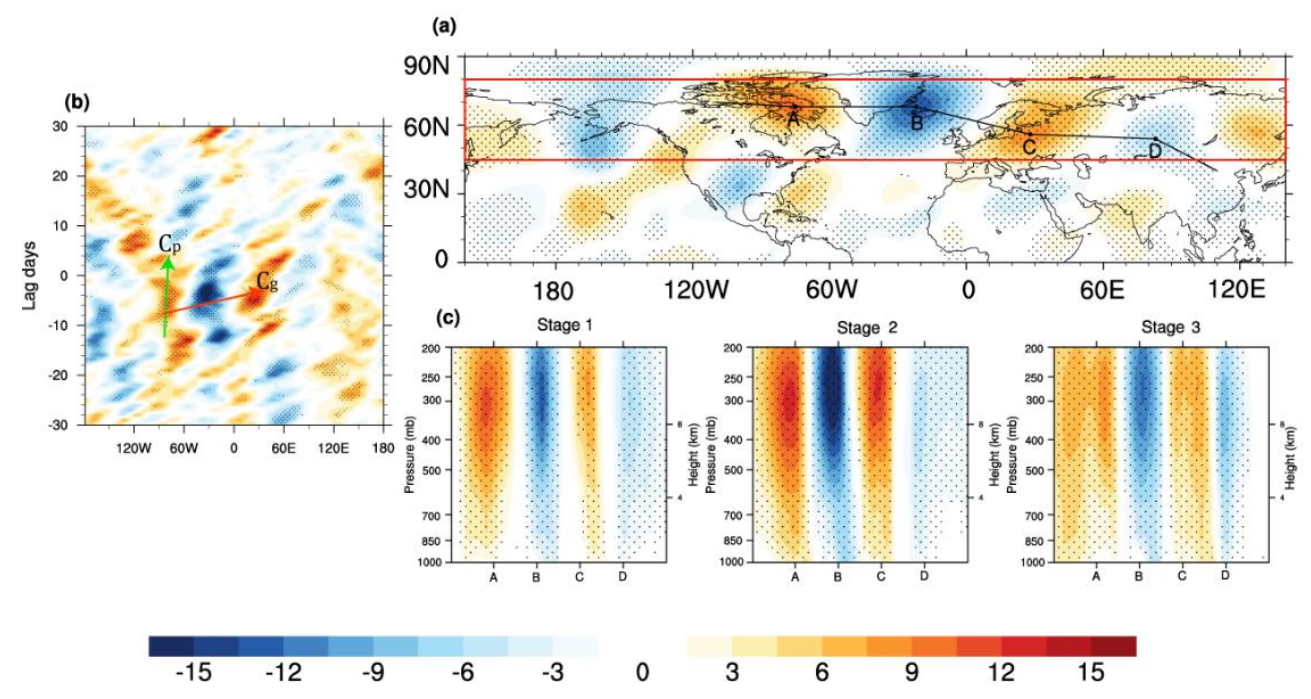


Fig.4 a The field of 250-hPa anomalous meridional wind ( $\left.v^{\prime}\right)$ (unit: $\mathrm{m} \mathrm{s}^{-1}$ ) averaged in three stages. $\mathbf{b}$ Composite Hovmoller diagram of the $250-\mathrm{hPa} v^{\prime}$ averaged in $45-80^{\circ} \mathrm{N}$ (red box in a). $\mathbf{c}$ Vertical section

270 of $v^{\prime}$ in three stages along the line as indicated in a. Dotted areas denote significant differences exceeding $95 \%$ confidence level

To learn more about the development process of the RWPs, Fig. 5 shows the anomalous distribution of meridional and zonal winds and T-N wave activity flux in the upper troposphere. It shows there are two columns of RWPs in stage 1 (Fig.5a), as mentioned above. In stage 2 (Fig.5b), however, the western side of RWPs in the Pacific disappears, and the WAF transported from eastern Greenland to downstream reinforces in the Atlantic. Meanwhile, the negative westerly anomalies in the mid-Atlantic to Norwegian sea intensify, which are conducive to the progress of the Rossby wave (Francis and Vavrus 2012), thus the RWPs on the eastern side strengthen and develop. Afterward, the WAF transmits to Eurasia in stage 3 , leading to the beginning of the cold event.

In general, it is known that the westerly momentum plays a crucial dynamic role in the development and propagation of the Rossby wave (Takaya and Nakamura 2001; Wirth et al. 2016). But what causes the disturbance of this wave train? Next, we will examine the formation mechanism for these RWPs at Baffin Bay area, where the first wave packet is situated.

(a)
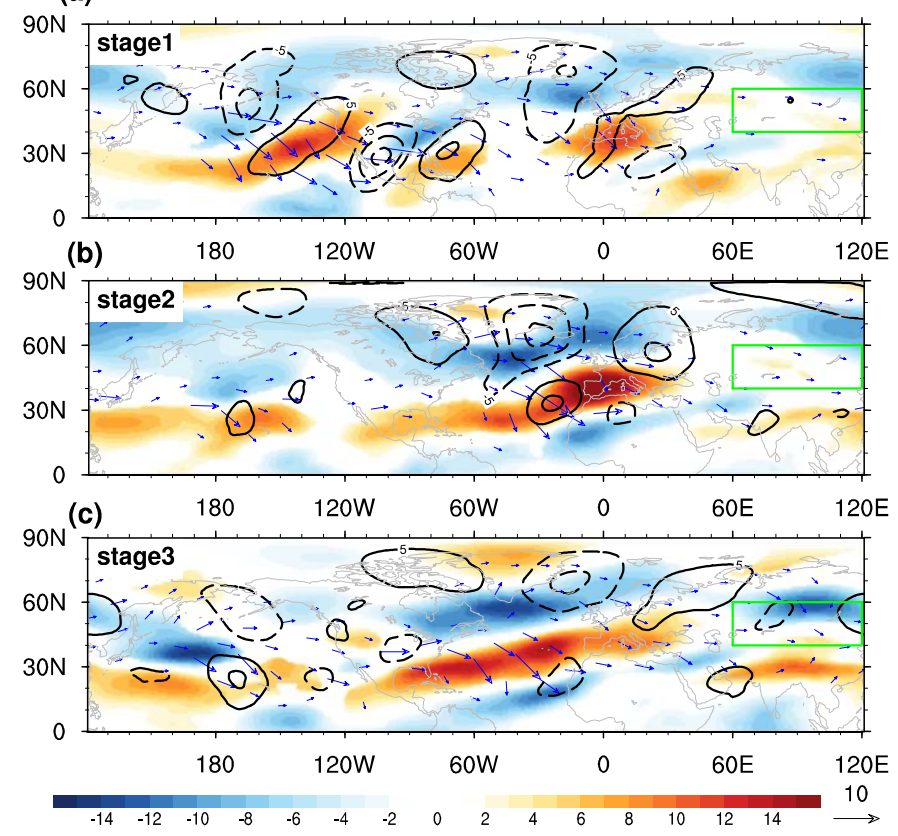

Fig. 5 Averaged composite fields of anomalous meridional wind (contour, unit: $\mathrm{m} \mathrm{s}^{-1}$ ) and zonal winds (shading, unit: $\mathrm{m} \mathrm{s}^{-1}$ ) and T-N wave flux (vector, unit: $\mathrm{m}^{2} \mathrm{~s}^{-2}$ ) at 200-hPa in a stage 1, b stage 2, c stage 

and contour denote significant differences exceeding 95\% confidence level

To examine the driving source of the disturbance, the time-evolution fields of meridional averaged of vertical WAF, and geopotential height anomalies over the Baffin Bay area $\left(30^{\circ} \mathrm{W}-90^{\circ} \mathrm{W}\right)$ before stage

2911 are illustrated in Fig. 6. It shows that there is a positive center of anomaly that appears in the upper stratosphere at lag -28 days (Fig.6a), after which it begins to fall (Fig.6b), along with a downward propagating WAF in the middle stratosphere until lag -16 days (Figs.6b-e), corresponding to the initial period of the RWP over Baffin Bay emerging in Fig.4b. In this way, the initial disturbances in Baffin Bay are thus concluded by the downward spread of energy in the stratosphere. In addition, it is worth mentioning that there is an upward and northward propagation of WAF from $50^{\circ} \mathrm{N}-60^{\circ} \mathrm{N}$ at lag -16 to 13 days (Figs.6e-f), which exactly corresponds to the end position of the western RWPs over easternNorth Pacific that appeared in Fig.6a. Therefore, we suppose that the western RWPs in Fig.6a may also contribute some energy to the eastern RWPs, which explains why it disappears immediately in stage 2 (Fig.6b). Martius et al. (2010) also proposed that if multiple waveguides are close to each other, the RWPs may transfer from one waveguide to another.
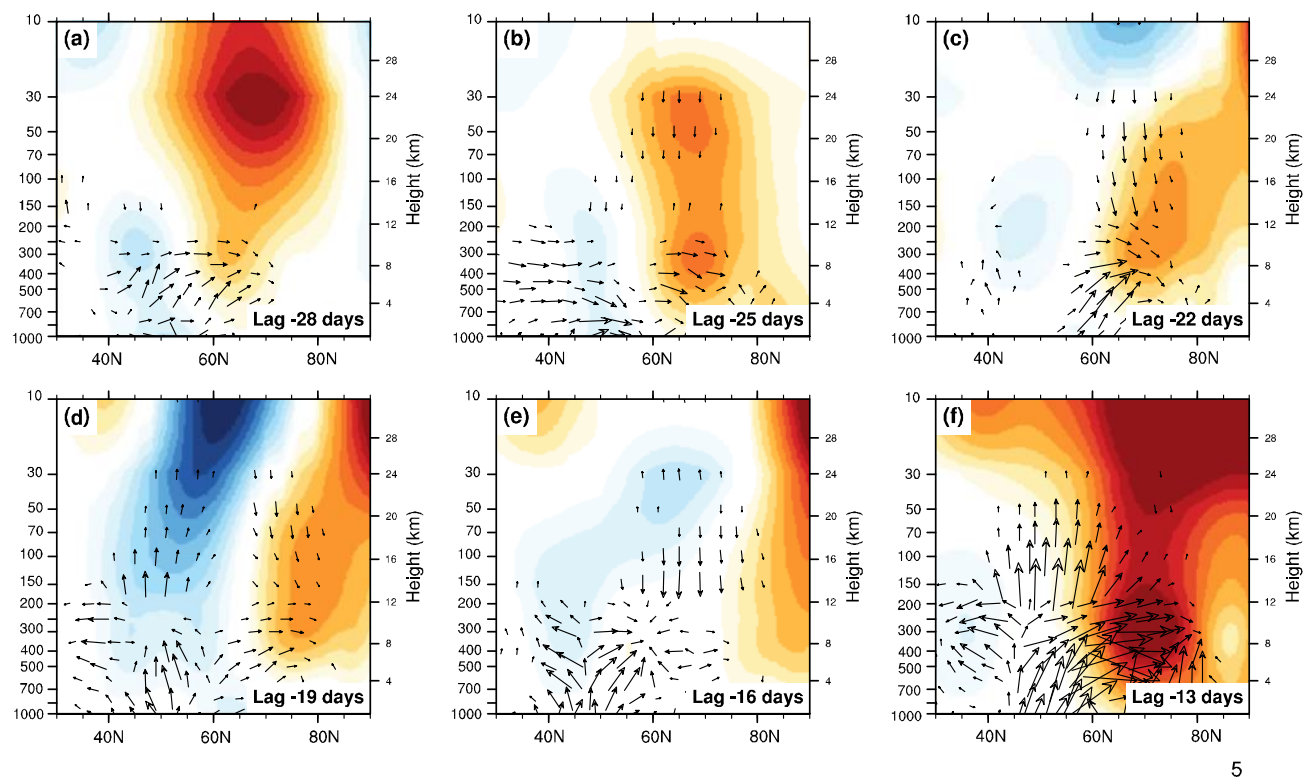

Fig.6 a-f Lead-lag composites of $30^{\circ} \mathrm{W}-90^{\circ} \mathrm{W}$ averaged cross section of geopotential height anomalies (shading; unit: gpm) and WAF (vectors; units: for horizontal component $\mathrm{m}^{2} \mathrm{~s}^{-2}$; for vertical component $10^{-2} \mathrm{~Pa} \mathrm{~m} \mathrm{~s}^{-2}$ ) based on type 1 event. The shading area indicates the anomalies of geopotential height exceeding $95 \%$ confidence level 


\section{2 type2: Pacific-origin}

For type 2 event, a similar analysis method is applied. As shown in Fig.7a, a column of RWPs begins from Hawaii Islands and extends to Europe. The Hovmoller diagram of latitude band of this wave train shown in Fig.7b exhibits that the RWPs begin to propagate eastward at about lag -9 days, with the same situation of faster group velocity as type 1, but with a shorter growth cycle. In Fig.7c, which presents three stages of vertical $v^{\prime}$ of the RWPs, apparent downstream development structure can be recognized: in stage 1, four weak RWP centers (A-D points) emerge in the upper troposphere; then, new RWPs appear downstream and reach maximum amplitude in stage 2 (D-F points), while the upstream wave packets recede quickly; in stage 3, similar with type 1 event, the cooling occurs and RWPs further fade away. Anyway, we know from the above analysis that these RWPs have different features and structures from type 1. Next, we will further investigate the formation mechanism of this wave train.

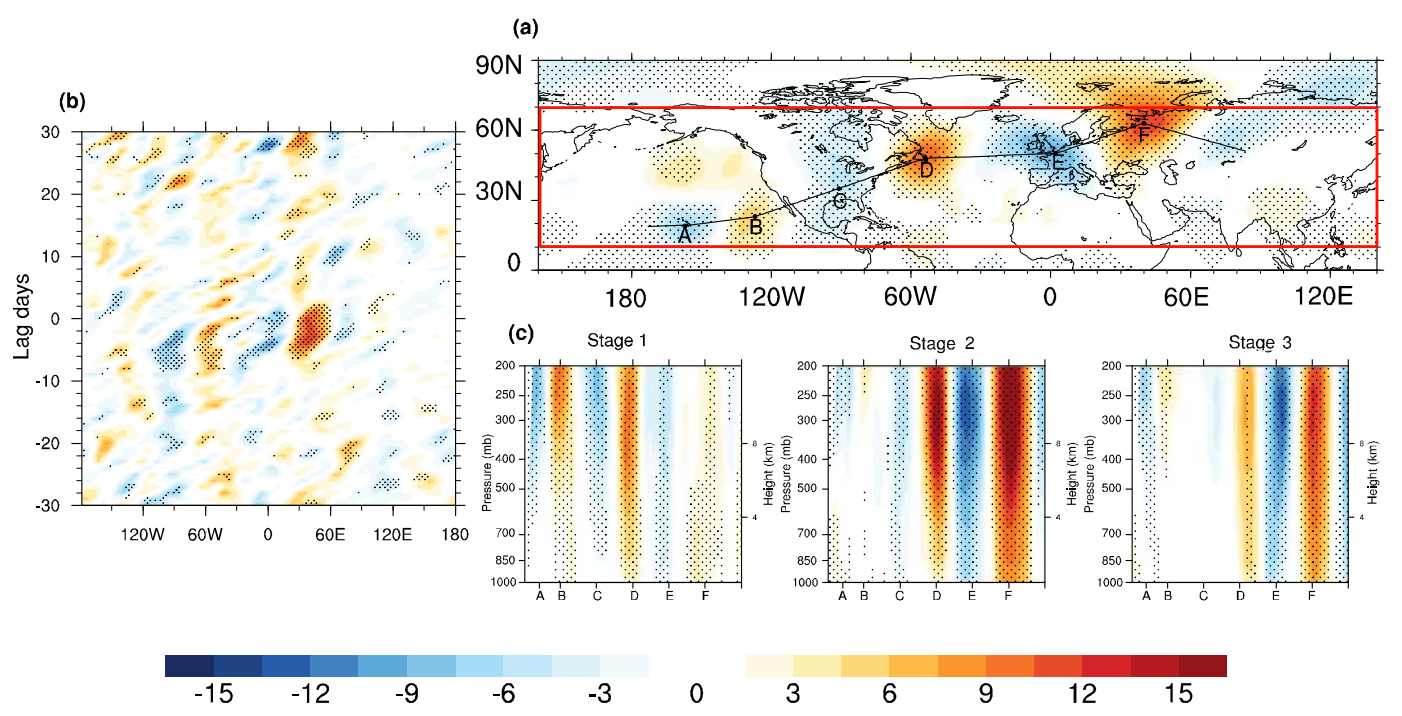

Fig.7 Same as in Fig. 4 but for type 2 event

Fig. 8 presents the anomalous distribution of meridional and zonal winds and WAF at the upper troposphere. In stage 1(Fig.8a), a distinct wave train appears from the central North Pacific to the western Atlantic; simultaneously, positive westerly anomalies in the central Pacific and negative westerly anomalies in the southern side of the Gulf of Alaska are observed. Furthermore, the configuration of upper-level divergence and lower-level convergence dominated the central Pacific (not shown). That is to say, in the middle of the North Pacific, where the outlet of the westerly jet is located, cyclonic shear and up-flow exist, which is conducive to the generation of cyclonic disturbance. Therefore, we speculate that the formation of these RWPs results from the increase of cyclonic shear over the outlet area of the 
westerly jet. Meanwhile, the westerly anomalies over North Atlantic are northerly, and enhance at stage 2 (Fig.8b), which may serve as a waveguide that further prompts the development of upstream wave packets to the European continent. It can also be seen from the evolution of WAF that the arrows follow the northerly westerlies towards Europe. In stage 3 (Fig.8c), the RWPs in the upstream vanish, and the downstream RWPs develop to the cold event area. The previous study has pointed out that the RWPs in the North Pacific often seed new wave packets over the North Atlantic for it inclined to deviate from the zonal direction and propagate equatorward into the subtropics (Wirth et al. 2018). In our case, though, the northerly westerly anomalies over the Atlantic relay the wave train develop to the northern Eurasian continent rather than southward.

(a)
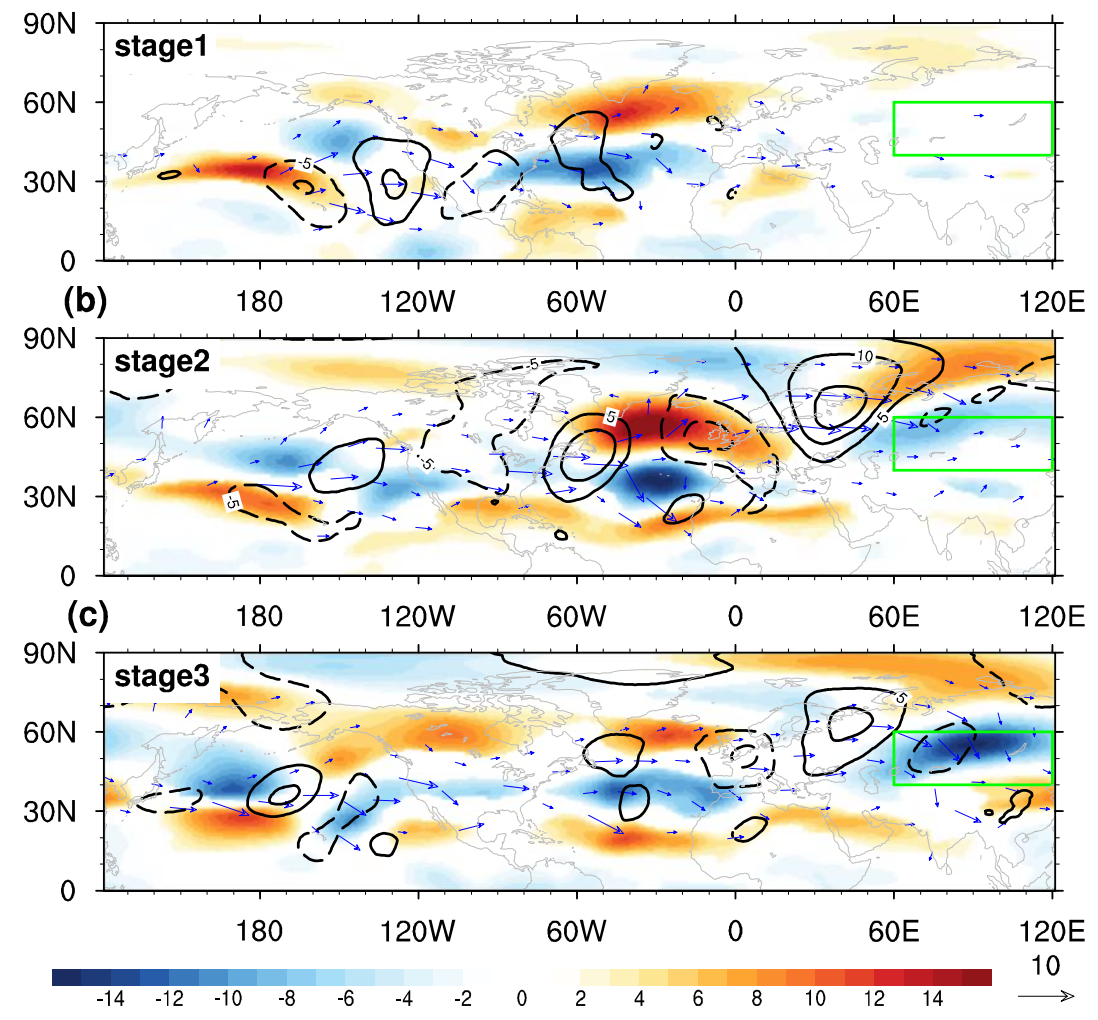

$338 \quad$ Fig. 8 Same as in Fig.5 but based on the type 2 event

\section{3 type 3: Atlantic-origin}

As shown in Fig.9, unlike the first two types of events, the averaged field of $v$ ' of type 3 event presents a dipole structure over the Greenland Sea and the Kara Sea, no prominent RWPs system that extended from upstream. Therefore, we speculate that this type of cold event may be related to some local development mechanism rather than the downstream development of remote RWPs like the first two types of events. 


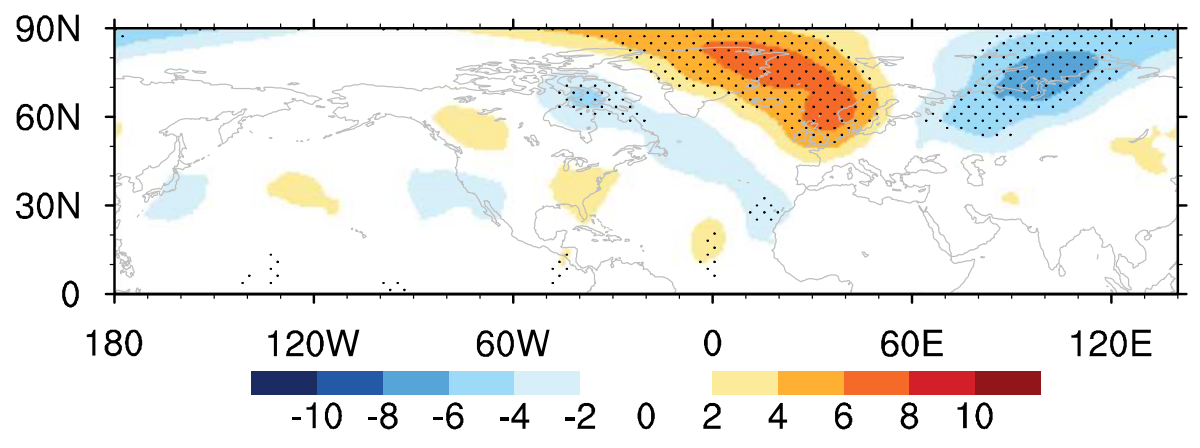

346 Fig.9 The averaged field of 250-hPa anomalous meridional wind ( $\left.v^{\prime}\right)$ in three stages of type 3 cold event.

347 Dotted areas denote significant differences exceeding $95 \%$ confidence level

348 To further understand its evolution process, the anomalous geopotential height and WAF fields in 349 the upper troposphere are given in Fig.10. It is shown that there is an anticyclone anomaly over 350 Scandinavia with two other opposite signs over the Atlantic and Northern Russia at stage 1; meanwhile, 351 the northeastward WAF originated from the middle of the Atlantic can be observed. Afterward, the 352 anticyclone anomalies develop to the strongest amplitude, along with enhanced WAF transport to the 353 downstream, resulting in the cooling over Eurasia in stage 3. Overall, this atmospheric system resembles 354 the teleconnection mode of the SCAND pattern, which may cause strong climate anomalies in the Arctic 355 and Eurasia (Wang and Tan 2020). There are various reasons that can lead to the formation of SCAND 356 patterns, such as the vorticity source over Western Europe (Liu et al. 2014), the Atlantic convective 357 heating or the height disturbance over the Arctic (Wang and Tan 2020), and the feedback forcing from 358 high-frequency eddies along the Atlantic storm track (Bueh and Nakamura 2007). 
(a)
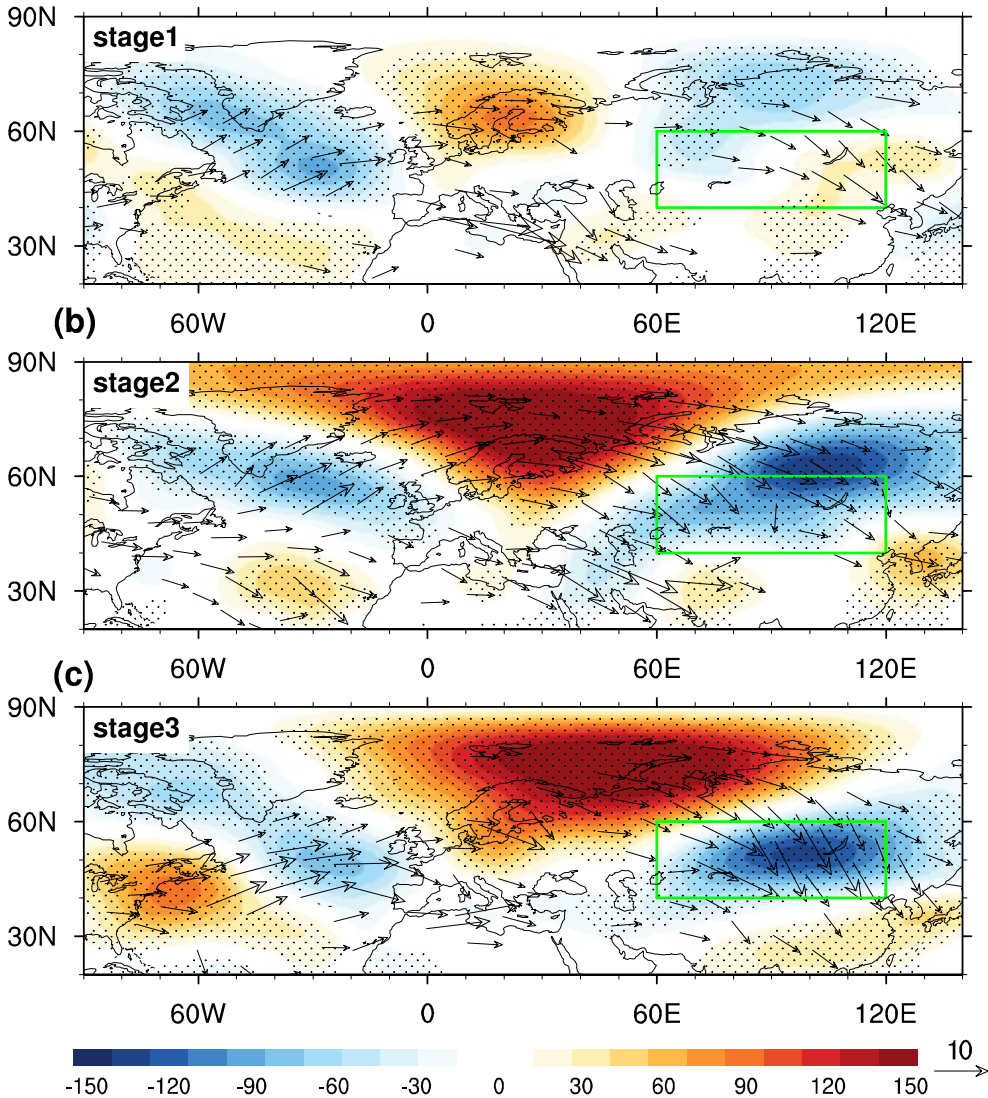

Fig.10 Averaged composite fields of 250-hPa geopotential height anomalies (shading; unit: gpm) and

361 WAF (vectors; unit: $\mathrm{m}^{2} \mathrm{~s}^{-2}$ ) of a stage 1, b stage 2, c stage 3 based on type 3 event. Dotted areas denote significant differences of the anomalies of geopotential height exceeding $95 \%$ confidence level

To confirm the influential role of the Atlantic, Fig.11 examines the anomaly of sea surface temperature, turbulent heat flux, and potential velocity and divergent wind in the upper troposphere averaged of stages 1-2 over mid-North Atlantic. The warm SST anomalies can be observed over the central Atlantic (Fig.11a); furthermore, the upward turbulent flux anomalies (negative area) showing up in the warm water area (Fig.11b), indicating that the force of SST to atmosphere exists; Meanwhile, the anomalous lower-tropospheric convergence (omitted) and upper-tropospheric divergence present over the warm SST region (Fig.11c). Therefore, the wave train may be excited by the sea-air interaction process due to the warm SST anomalies over the North Atlantic. The result is different from Liu et al.

371 (2014), who pointed out that the upper-tropospheric divergent flow induced by the Indian Ocean heating

372 could lead to divergence anomalies over the Mediterranean and subsequently motivate the formation of the SCAND pattern. In our work, the divergence flow is related to the warm SST over the Atlantic. 


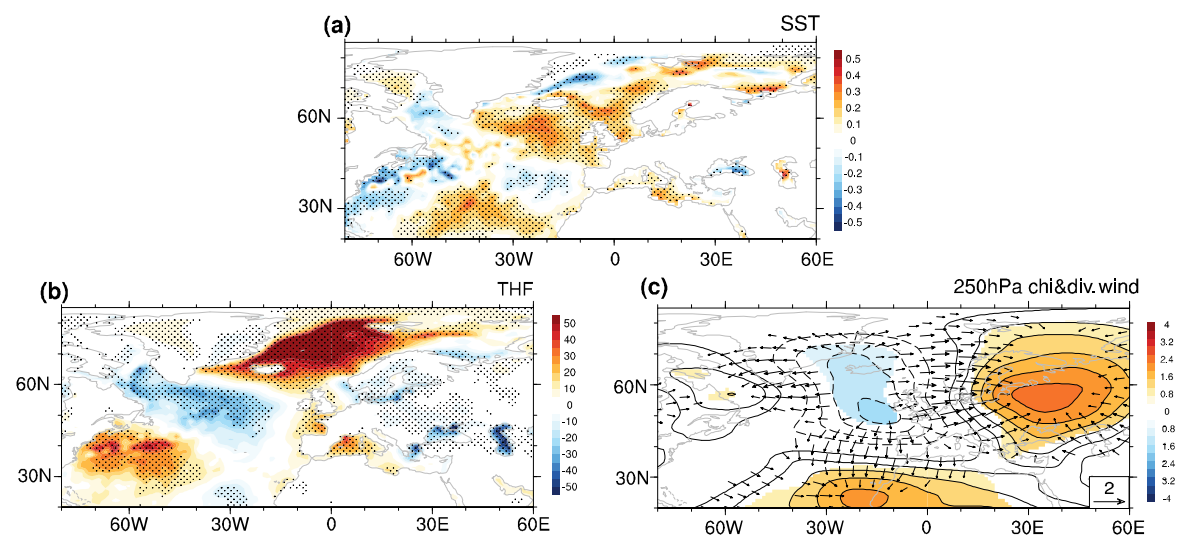

375 Fig.11 The averaged anomalous field of a SST (unit: K) b THF (unit: $\mathrm{W} \mathrm{m}^{-2}$ ) c 250-hPa velocity potential (unit: $1 \times 10^{6} \mathrm{~m}^{2} \mathrm{~s}^{-1}$ ) and divergent wind (unit: $\mathrm{m} \mathrm{s}^{-1}$ ) based on stage1-2 of type 3 event. Dotted areas in $\mathbf{a}-\mathbf{b}$ and shading area and vectors in $\mathbf{c}$ denote significant differences exceeding $95 \%$ confidence level

\section{Summary and discussions}

In this work, we categorize the extreme cold events over central Eurasia into three groups from the perspective of precursory atmospheric disturbance. According to the classification, each category of the anomalous atmospheric modes is found to be associated with Rossby wave trains originating from different positions. Fig.12 presents the atmospheric disturbance origin and development path of three types of events. For type 1 (Fig.12a), two branches of RWPs can be clearly seen. It is the one located at the Baffin Bay to Europe continent that affects the cooling over Eurasia, which is generated by the stratospheric downwards energy over the Baffin Bay; besides, the one on the left side may also play a role. When the RWPs propagate eastward, with group velocity larger than phase velocity, they reach maximum amplitude prior to the advent of cold event, which may serve as a precursor signal of cooling eruption. For type 2 (Fig.12b), the westerlies play a crucial role. Firstly, the disturbance generates at the exit of the westerly jet over the North Pacific, where cyclone shear exists, then propagates downstream as wave packets; after that, the northerly westerlies over North Atlantic extend the wave train to the Eurasian continent, with the same downstream development situation like type1, leading to the outbreak of extreme cooling. In many studies, the RWPs are usually found in the subtropical westerly jet over Asia

394 (Watanabe 2004), which can easily affect the precipitation over south China (Li and Sun 2015; Hu et al. 2018; Sun and Guan 2020). In this work, however, the westerlies over North Atlantic can also act as a waveguide. For type 3 (Fig.12c), the SCAND-like mode presents over the Atlantic to Europe, but no 

this type may be triggered by the process of sea-air interaction over the mid-North Atlantic.

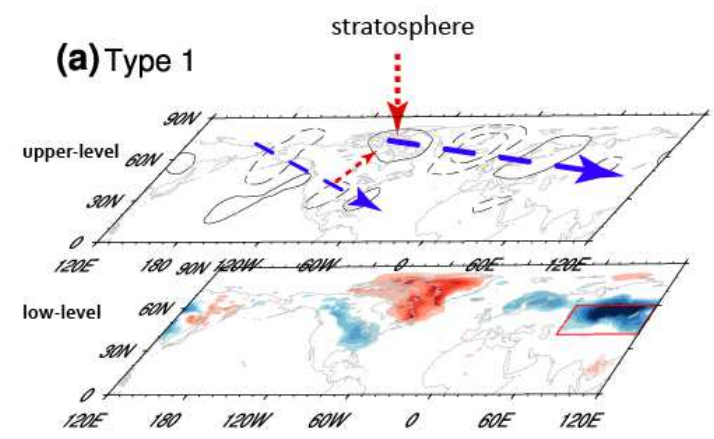

\section{(b) Type 2}

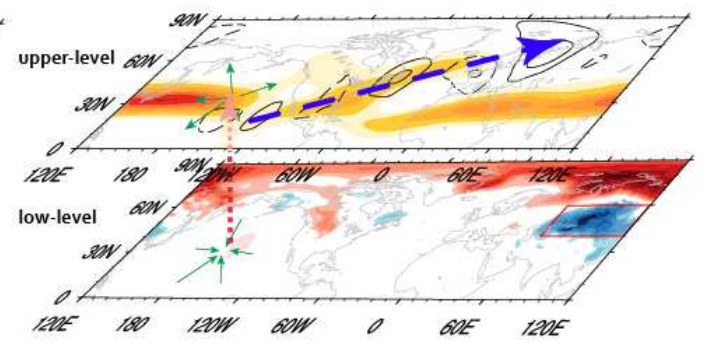

\section{(c) Type 3}

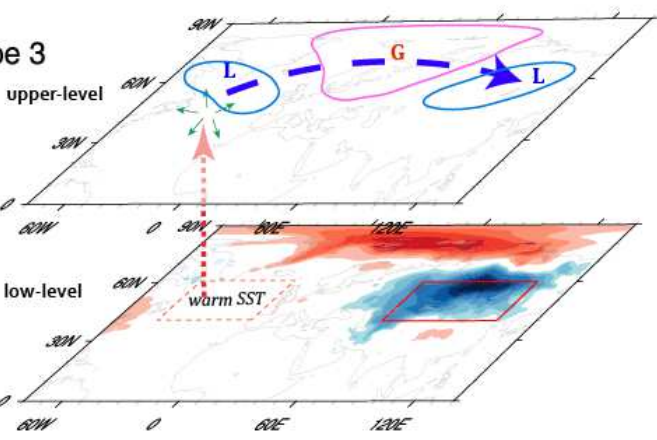

Fig.12 Schematic diagram for three types of events showing the development source and propagation path of Rossby wave packets in stage 1-2 (upper-level) and their effect on the surface temperature in stage 3 (low-level) of a type 1, $\mathbf{b}$ type 2, $\mathbf{c}$ type 3 event. In the upper-level, the contour in $\mathbf{a}$ and $\mathbf{b}$ indicate the meridional wind anomalies, the contour in $\mathbf{c}$ denote the geopotential height anomalies, and the yellow shading area in $\mathbf{b}$ indicates the zonal wind; the blue dash arrows signify the development direction of the wave train, and the red dash arrows in a denote the direction of energy transfer. In the low-level, the shading area represents the anomalies of surface air temperature on stage 3 (blue denote negative anomaly, red denote positive anomaly)

As discussed in Wirth et al. (2018), there is no clear answer yet whether the presence of precursor RWPs helps to improve the prediction of the extreme weather, which hinges on the systematic contacts between RWPs and extreme weather. In our work, the first two types of events possess apparently RWPs signals about 10 days before the occurrence of extreme cooling but not the third event, which verifies the uncertainty of the link between extreme weather and precursor RWPs, but also suggests that the RWPs can indeed act as a precursor signal of extreme cooling to some extent. In other words, the results have some indicative implications for the improvement of weather extended forecast. Certainly, it is not enough to illuminate the connection from a small sample of extreme cases we selected, thus more 
416 possible mechanisms of precursory wave trains that can lead to extreme weather remains to be explored 417 in the future.

In addition, since we divide the cold events based on the atmospheric circulation, some external force factors that may also relate to Eurasia cooling, such as the warming of the Arctic (Cohen 2016; Ma et al. 2018, Mori et al. 2019), are not presenting distinctly in our cases due to the composite analysis.

421 Consequently, further studies that probe into various outside factors on the Rossby wave train that lead to extreme cooling deserve to be explored.

\section{Acknowledgements}

443 This work was supported by the National Key Scientific Research Program of China (2019YFA0607004), 444 the National Science Foundation of China (42075024) and Shandong Natural Science Foundation Project 445 (ZR2019ZD12). 


\section{Reference}

Barton Y, Giannakaki P, von Waldow H, Chevalier C, Pfahl S, Martius O (2016) Clustering of regional-scale extreme precipitation events in southern Switzerland. Mon Wea Rev 144(1): 347369. https://doi.org/10.1175/MWR-D-15-0205.1

Barnston AG, and Livezey RE (1987) Classification, seasonality and persistence of low-frequency atmospheric circulation patterns. Mon Wea Rev 115:1083-1126. https://doi.org/10.1175/15200493(1987)115,1083:CSAPOL.2.0.CO;2

Bosart LF, Moore BJ, Cordeira JM, Archambault H M (2017) Interactions of North Pacific tropical, midlatitude, and polar disturbances resulting in linked extreme weather events over North America in October 2007. Mon Wea Rev 145:1245- 1273. https://doi.org/10.1175/MWR-D-16$\underline{0230.1}$

Bueh C, Nakamura H (2007) Scandinavian pattern and its climatic impact. Q J Roy Meteor Soc 133: 2117-2131. https://doi.org/10.1002/qj.173

Branstator, G (2002) Circumglobal teleconnections, the jet stream waveguide, and the North Atlantic Oscillation. J Clim 15(14), 1893-1910. https://doi.org/10.1175/15200442(2002)015h1893:CTTJSWi2.0.CO;2

Casado MJ, Pastor MA, Doblas-Reyes FJ (2009) Euro-Atlantic circulation types and modes of variability in winter. Theor Appl Climatol 96:17-29. https://doi.org/10.1007/s00704-008-0036-2

Chang, and Yu DB, (1999) Characteristics of wave packets in the upper troposphere Part I: Northern Hemisphere winter. J Atmos Sci 56:1708-1728.https://doi.org/10.1175/15200469(1999)056,1708: COWPIT.2.0.CO;2

Chen S, Wu R, Chen W, Hu K, Yu B (2020) Structure and dynamics of a springtime atmospheric wave train over the North Atlantic and Eurasia. J Clim 54(11-12): 5111-5126. https://doi.org/10.1007/s00382-020-05274-7

Cohen JL, Furtado JC, Barlow M, Alexeev VA, Cherry JE (2012) Asymmetric seasonal temperature trends. Geophys Res Lett, 39(4): 1-7. https://doi.org/10.1029/2011GL050582

Cohen J, Screen J, Furtado J et al (2014) Recent Arctic amplification and extreme mid-latitude weather. Nature Geosci 7:627-637. https://doi.org/10.1038/ngeo2234

Cohen J. (2016) An observational analysis: Tropical relative to Arctic influence on midlatitude weather in the era of Arctic amplification. Geophys Res Lett 6: 1-402. https://doi.org/10.1002/2016GL069102 
Cohen J, Zhang X, Francis J et al (2020) Divergent consensuses on Arctic amplification influence on midlatitude severe winter weather. Nat Clim Change 10:20-29. https://doi.org/10.1038/s41558019-0662-y

Dee DP et al (2011) The ERA-Interim reanalysis: configuration and performance of the data assimilation system. Q J R Meteorol Soc 137:553-597. https ://doi.org/10.1002/qj.828

Francis JA, Vavrus SJ (2012) Evidence linking Arctic amplification to extreme weather in midlatitudes. Geophys Res Lett 39:L06801. http://dxdoi.org/10.1029/2012GL051000

Fragkoulidis G, Wirth V, Bossmann P, Fink AH (2018) Linking Northern Hemisphere temperature extremes to Rossby wave packets. Q J Roy Meteor Soc 144(711):553-566. https://doi.org/10.1002/qj.3228

Grazzini F, Fragkoulidis G, Teubler F, Wirth V, Craig GC (2021) Extreme precipitation events over northern Italy. Part II: Dynamical precursors. Q J R Meteorol Soc 147:1237- 1257. https://doi.org/10.1002/qj.3969

Gong Z, Feng G, Ren F, Li, J (2014) A regional extreme low temperature event and its main atmospheric contributing factors. Theor Appl Climatol 117(1):195-206. https://doi.org/10.1007/s00704-013-0997-7

Glatt I, Dörnbrack A, Jones S, Keller J, Martius O, Müller A, Peters DHW, Wirth V (2011) Utility of Hovmöller diagrams to diagnose Rossby wave trains. Tellus A 63(5):991-1006. https://doi.org/10.1111/j.1600-0870.2011.00541.x

Horton DE, Johnson NC, Singh D, Swain DL, Rajaratnam B, Diffenbaugh NS (2015) Contribution of changes in atmospheric circulation patterns to extreme temperature trends. Nature 522(7557):465-469. https://doi.org/10.1038/nature14550

Hu K, Huang G, Wu R, Wang L (2018) Structure and dynamics of a wave train along the wintertime Asian jet and its impact on East Asian climate. Clim Dyn 51(11-12):4123-4137. https://doi.org/10.1007/s00382-017-3674-1

Hoskins BJ, Ambrizzi T (1993) Rossby wave propagation on a realistic longitudinally varying flow. J Atmos Sci 50:1661-1671. https://doi.org/10.1175/1520-0469(1993)050,1661: RWPOAR.2.0.CO;2

Kretschmer M, Cohen J, Matthias V, Runge J, Coumou D (2018). The different stratospheric influence on cold-extremes in Eurasia and North America. Npj Clim Atmos Sci 1(1):1-10. https://doi.org/10.1038/s41612-018-0054-4

Krishnamurti TN, Molinari J, Pan H, and Wong V (1977) Downstream amplification and formation of monsoon disturbances. Mon Wea Rev 105:1281-1297. https://doi.org/10.1175/15200493(1977)105<1281:DAAFOM>2.0.CO;2 
Kosaka Y, Nakamura H, Watanabe M, Kimoto M (2009) Analysis on the dynamics of a wave-like teleconnection pattern along the summertime Asian jet based on a reanalysis dataset and climate model simulations. J Meteor Soc Jpn 87(3):561-580. https://doi.org/10.2151/jmsj.87.561

Kug JS, Jeong JH, Jang YS, Kim BM, Folland CK, Min SK, Son SW (2015). Two distinct influences of Arctic warming on cold winters over North America and East Asia. Nat Geosci 8(10):759762. https://doi.org/10.1038/ngeo2517

Kim KY, Son SW (2016) Physical characteristics of Eurasian winter temperature variability. Environ Res Lett 11(4):044009. https://doi.org/10.1088/1748-9326/11/4/044009

Li C, Sun J (2015) Role of the subtropical westerly jet waveguide in a southern China heavy rainstorm in December 2013. Adv Atmos Sci 32(5):601-612. https://doi.org/10.1007/s00376-014-4099-y

Liu Y, Wang L, Zhou W, Chen W (2014) Three Eurasian teleconnection patterns: Spatial structures, temporal variability, and associated winter climate anomalies. Clim Dyn 42(11-12):2817-2839. https://doi.org/10.1007/s00382-014-2163-z

Lu C, Xie S, Qin Y, Zhou J (2016) Recent Intensified Winter Coldness in the Mid-High Latitudes of Eurasia and Its Relationship with Daily Extreme Low Temperature Variability. Adv Meteorol 2016:17-19. https://doi.org/10.1155/2016/3679291

Luo D, Xiao Y, Yao Y, et al (2016) Impact of ural blocking on winter warm Arctic-cold Eurasian anomalies. Part I: Blocking-induced amplification. J Clim 29:3925-3947. https://doi.org/10.1175/JCLI-D-15-0611.1

Luo D, Xiao Y, Diao Y, et al (2016) Impact of Ural blocking on winter warm Arctic-cold Eurasian anomalies. Part II: The link to the North Atlantic Oscillation. J Clim 29:3949-3971. https://doi.org/10.1175/JCLI-D-15-0612.1

Luo B, Wu L, Luo D, Dai A, Simmonds I (2019) The winter midlatitude-Arctic interaction: effects of North Atlantic SST and high-latitude blocking on Arctic sea ice and Eurasian cooling. Clim Dyn 52(5-6):2981-3004. https://doi.org/10.1007/s00382-018-4301-5

Martius O, Schwierz C, Davies HC (2010) Tropopause-level waveguide. J Atmos Sci 67(3):866-879. https://doi.org/10.1175/2009JAS2995.1

Ma S, Zhu C, Liu B, Zhou T, Ding Y, Orsolini YJ (2018) Polarized response of East Asian winter temperature extremes in the Era of arctic warming. J Clim 31(14):5543-5557. https://doi.org/10.1175/JCLI-D-17-0463.1

Mori M, Kosaka Y, Watanabe M, Nakamura H, Kimoto M (2019) A reconciled estimate of the influence of Arctic sea-ice loss on recent Eurasian cooling. Nat Clim Change 9(2):123-129. https://doi.org/10.1038/s41558-018-0379-3 
Overland JE, Wang MY (2010) Large-scale atmospheric circulation changes are associated with the recent loss of Arctic sea ice. Tellus A 62(1):1-9. https://doi.org/10.1111/j.1600$\underline{0870.2009 .00421 . x}$

Persson A (2017) The story of the Hovmöller diagram-An (almost) eyewitness account. Bull Amer Meteor Soc 98:949-957. https://doi.org/10.1175/BAMS-D-15-00234.1

Sato K, Inoue J, Watanabe M (2014) Influence of the Gulf Stream on the Barents Sea ice retreat and Eurasian coldness during early winter. Environ Res Lett 9(8):84009. https://doi.org/10.1088/1748-9326/9/8/084009

Sun S, Guan, Z (2020) Rossby wave packets in the upper troposphere and their associations with climatological summertime daily precipitation in MLRYR of China. Atmos Sci Lett 1-9. https://doi.org/10.1002/asl.1023

Shi N, Bueh C, Ji LR, Wang PX (2009) The impact of mid- and high-latitude Rossby wave activities on the medium-range evolution of the EAP pattern during the pre-rainy period of South China. Acta Meteorologica Sinica 23(3):300-314. https://doi.org/10.1016/S1003-6326(09)60084-4

Shi J, Wu K, Qian W, et al (2021) Characteristics, trend, and precursors of extreme cold events in northwestern North America. Atmos Res 249:105338. https://doi.org/10.1016/j.atmosres.2020.105338

Takaya K, Nakamura H (2001) A formulation of a phase-independent wave-activity flux for stationary and migratory quasi geostrophic eddies on a zonally varying basic flow. J Atmos Sci 58:608-627

Wallace JM, Gutzler DS (1981) Teleconnections in the geopotential height field during the Northern Hemisphere winter. Mon Wea Rev 109:784-812. https://doi.org/10.1175/15200493(1981)109<0784:TITGHF $>2.0 . \mathrm{CO} ; 2$

Watanabe M (2004) Asian jet waveguide and a downstream extension of the North Atlantic oscillation. J Clim 17:4674-4691. https://doi.org/10.1175/1520-0469(1993)050<2038:DDOBWA>2.0.CO;2

Wang M, Tan B (2020) Two types of the Scandinavian pattern: Their formation mechanisms and climate impacts. J Clim 33(7):2645-2661. https://doi.org/10.1175/JCLI-D-19-0447.1

Wirth V, Eichhorn J (2014) Long-lived Rossby wave trains as precursors to strong winter cyclones over Europe. Q J Roy Meteor Soc 140(680):729-737. https://doi.org/10.1002/qj.2191

Wirth V, Riemer M, Chang EKM, Martius O (2018) Rossby wave packets on the midlatitude waveguideA review. Mon Wea Rev 146(7):1965-2001. https://doi.org/10.1175/MWR-D-16-0483.1

Wu B, Yang K, Francis JAA (2017) Cold Event in Asia during January-February 2012 and Its Possible Association with Arctic Sea Ice Loss. J Clim 30(19):7971-7990. 
575

576

577

578

579

580

581

582

Zhang X, Lu C, Guan Z (2012) Weakened cyclones, intensified anticyclones and recent extreme cold winter weather events in Eurasia. Environ Res Lett 7(4): 044044. https://doi.org/101088/17489326/7/4/044044

Zheng Fei, Yuan Y, Ding YH, Li Kexin et al. (2021). The 2020/21 Extremely Cold Winter in China Influenced by the Synergistic Effect of La Niña and Warm Arctic. Advances in Atmospheric Sciences. 10.1007/s00376-021-1033-y.

Zhuo WQ, and Jiang ZN (2020) Possible links between Arctic sea ice loss and Eurasian cold winter events. J Meteor Res 34(6):1214-1225. https://doi.org/10.1007/s13351-020-0052-4.1 


\section{Supplementary Files}

This is a list of supplementary files associated with this preprint. Click to download.

- SupplementaryInformation.pdf 